\title{
What All We Should Know About Masks in COVID-19 Pandemic
}

\author{
Himanshu Agrawal ${ }^{1}$ (D) $\cdot$ Sweta Singh ${ }^{2} \cdot$ Nikhil Gupta $^{1}$
}

Received: 29 May 2020 / Accepted: 5 June 2020 / Published online: 99lune 2020

(C) Association of Surgeons of India 2020

\section{Dear Editor in Chief,}

Coronavirus disease 2019 (COVID-19) has been declared as a pandemic by the World Health Organization. Worldwide over 5,880,000 patients have been infected and over 350,000 fatalities have occurred till date. Coronavirus is a large virus with average diameter of around $125 \mathrm{~nm}$ [1]. The most common mode of spread of this virus is through aerosols from an infected person [2]. Many people are therefore wondering if masks can capture coronavirus particles.

General population and even the health care workers (HCW) know very less about the types of masks available and their proper use This knowledge gap can cause some serious harm in the society.

This article aims to provide information about the commonly available masks and their proper use.

1. Surgical masks/Triple layer masks:

It is composed of three layers. The outermost is made of hydrophobic material, middle one is a filter layer, and the innermost is an absorbent layer intended to absorb moisture from the breath. It has a life span of 3 to $8 \mathrm{~h}$ and should never be washed and reused. The pleats provided are designed to increase the surface area of the mask. They reduce aerosol transmission by $50 \%$ and offer 75-80\% protection from getting the disease.

2. Respirator masks:

These include N95, N99, N100, FFP1, FFP2, and FFP3 masks. Further, it can either be with valve or

Himanshu Agrawal

himagr1987@gmail.com

1 Department of Surgery, Atal Bihari Vajpayee Institute of Medical Sciences and Dr. Ram Manohar Lohia Hospital, New Delhi, India

2 Department of Dermatology, Atal Bihari Vajpayee Institute of Medical Sciences and Dr. Ram Manohar Lohia Hospital, New Delhi, India

without valve. The valved masks provide free exit of exhaled breath making them useless for patients who are suffering form COVID-19. A typical respirator mask is firstly a tight fit mask that prevents any air leak [3]. Secondly, it has an air filtering unit, composed of stacks of millions of electrostatically charged polypropylene microfibers. To efficiently filter microorganisms, this charge is of utmost importance. The categorization into N95, N99, and N100 depends upon the filtration efficacy of the mask. N95 masks can filter around $95 \%$ of particles which are $>0.3 \mu \mathrm{m}$ size, whereas N99 can filter $99 \%$ of these.

All these masks can effectively filter coronavirus provided that there is no air leak. The biggest disadvantage with these masks is that they are not easy to breath and become uncomfortable on prolonged use. Therefore, they are only meant for HCW who come in direct contact with COVID-19 patients. These masks reduce aerosol transmission by $70 \%$ and offer $99 \%$ protection from getting the disease.

3. Dust mask and single layer mask:

They do not offer any protection against coronavirus.

\section{Cloth masks:}

It is a cheap, washable, and an easily available alternative of surgical mask for general population especially in developing countries. These masks reduce aerosol transmission by $40 \%$ and offer $50-70 \%$ protection from getting the disease.

In conclusion, wearing any mask is better than wearing no mask, both in terms of transmission and protection. For community at large, surgical mask is preferred. Alternatively, 3layer cotton mask can be used.

For HCW in outpatient department, a surgical mask is recommended.

Respirator masks along with a personal protective equipment should be used by an HCW during aerosol generating procedures in a COVID-19 patient. 


\section{Compliance with Ethical Standards}

Conflict of Interest The authors declare that they have no conflict of interest.

\section{References}

1. Goldsmith CS, Tatti KM, Ksiazek TG, Rollin PE, Comer JA, Lee WW, Rota PA, Bankamp B, Bellini WJ, Zaki SR (2004) Ultrastructural characterization of SARS coronavirus. Emerg Infect Dis 10(2):320-326
2. Lee J, Yoo D, Ryu S, Ham S, Lee K, Yeo M, Min K, Yoon C (2019) Quantity, size distribution, and characteristics of cough-generated aerosol produced by patients with an upper respiratory tract infection. Aerosol Air QualRes 19:840-853

3. Smith JD, MacDougall CC, Johnstone J, Copes RA, Schwartz B, Garber GE (2016) Effectiveness of N95 respirators versus surgical masks in protecting health care workers from acute respiratory infection: a systematic review and meta-analysis. Cmaj. 188(8):567-574

Publisher's Note Springer Nature remains neutral with regard to jurisdictional claims in published maps and institutional affiliations. 